\title{
SOBRE “EU NÃO QUERO VOLTAR SOZINHO” EM SALA DE AULA
}

\author{
Lídia Lobato Leal ${ }^{1}$
}

A presente reflexão se dá a partir de um módulo de aulas da disciplina Arte, realizada no Instituto Federal de Educação, Ciência e Tecnologia Goiás - Campus Goiânia, em 2015. O módulo era "Quem sou eu?" e foi aplicado em turmas do $1^{\circ}$ ano do Ensino Técnico Integrado ao ensino médio em Eletrotécnica, Instrumento musical e Controle Ambiental.

Na modalidade Técnica Integrada ao Ensino Médio, o/a discente estuda as disciplinas básicas do ensino médio formal integrado às disciplinas da formação profissional à que está vinculado/a via prova de acesso.

A disciplina Arte, no IFG é oportunizada aos/as discentes tendo como proposta as quatro linguagens da arte (dança, teatro, música e artes visuais) que por estarem apenas no $1^{\circ}$ ano do ensino médio são trabalhadas pelos/as professores/as especializados/as em cada uma das linguagens, no prazo de um semestre.

Dentro deste módulo "Quem sou eu?", busquei trabalhar, em artes visuais, com os atravessamentos que a pergunta gera. Com as produções de sentidos amparadas pela diversidade étnica, de gênero, sexual e religiosa. Os objetivos eram: experimentar/fruir, debater e produzir imagens (fotográficas e vídeos) que deveriam ser debatidas novamente quando de sua exibição em sala de aula.

Além das referências bibliográficas de artes, também utilizei referências visuais com obras de Sammy Sfoggia, Yasumasa Morimura e Frida Khalo. Referências áudio visuais foram: "Uma história de amor e Fúria"2, "Eu não quero voltar sozinho"3 e trechos de "Yndio do Brasil" ". Todas essas referências buscavam alinhavar a proposta da experimentação em arte, do debate sobre o tema "quem sou eu?" expandindo para uma educação pela diversidade através da exibição dos trabalhos dos alunos e das imagens (tanto paradas quanto vídeos/filmes).

Quando o filme de 17 minutos "Eu não quero voltar sozinho" foi apresentado em sala de aula, especificamente na turma do curso de Eletrotécnica, tínhamos visto imagens de Yasumasa Morimura, travestido de Frida khalo na semana anterior, era uma fotografia onde o artista "reelabora", a partir de todo um reposicionamento de sentidos, a si mesmo como Frida Khalo. A discussão sobre este trabalho de Morimura solicitou dos alunos um esforço de transbordamento de subjetividades para entender as conexões sobre este "quem sou eu-outro?" que cada um de nós pode ser. Conversamos sobre arte, sobre feminismo, sobre sexualidade, sobre ser gente, sobre as peles craqueladas que teimam em ser contidas nos cubículos cartesianos, aquelas peles que se esgarçam para além desses limites e os possíveis porquês de Morimura escolher aquela forma de expressão para sua arte.

Na semana em que trabalhamos com a obra de Morimura, os/as discentes tinham que trazer uma atividade de colagem que deslocasse alguém de sua posição de conforto e convencionalismo da produção de subjetividades cultural e social. Fomos ver as colagens produzidas e mais uma vez muitas questões foram expostas, sempre nos pautando pelo respeito à diversidade humana em suas formas de expressão. Mas principalmente eu buscava me basear no "agridoce prazer da experimentação" (TADEU, 2004, p. 12) e propunha àqueles/as jovens também embrenharem-se no jardim rizomático proposto por Gilles Deleuze.

\footnotetext{
${ }^{1}$ Instituto Federal de Educação, Ciência e Tecnologia de Goiás- IFG, Doutoranda do Grupo OLHO/FE/UNUCAMP. E-mail: 1leal19@gmail.com.

${ }^{2}$ Luis Bolognesi, animação, Brasil, 2013.

${ }^{3}$ Daniel Ribeiro, Brasil, 2010.

${ }^{4}$ Sylvio Back, Brasil, 1995.
} 
Nessa atividade vimos corpos distorcidos, coloridos, maravilhosos e também assustadores, todos eles foram fruídos por todos os alunos presentes e foram expostas as formas de fazer, mas, principalmente as experiências e possibilidades que aquelas imagens apontavam.

A surpresa se deu quando fomos assistir " Eu não quero voltar Sozinho", onde inverti a ordem de experimentação para iniciar com um exercício de fruição, o que é muito comum em se tratando do ensino de arte. (Atenção: spoiller) Exatamente na cena ápice do filme (beijo entre os dois personagens principais) um aluno começa a xingar e falar alto que ele não era obrigado a ficar na sala vendo "pouca-vergonha", ficou muito nervoso e saiu. Eu não parei o filme, nem fui atrás para tentar conversar com ele, pois fiquei preocupada em como a turma reagiria à situação. Era uma turma de 26 alunos do curso de eletrotécnica, em sua maioria meninos. Então após o fim do filme fomos realizar o debate tanto sobre o ocorrido quanto sobre os possíveis porquês de tal reação. Ouvi dos alunos que era mesmo difícil ver um filme onde meninos da idade deles se beijavam que isso contrastava com o que tinham aprendido em casa, mas que estavam percebendo que amor, é amor, independente de ser entre meninos com meninos ou meninas com meninas. Confessaram que existe uma enorme pressão da parte da família e da sociedade para que sigam padrões preestabelecidos e que era muito difícil viver seguindo tais expectativas. Foi uma conversa muito enriquecedora, pois aqueles adolescentes sentiram, experimentaram a possibilidade de expressarem as pressões a que estão expostos.

Depois tentei conversar com o aluno que saiu da sala, mas ele nunca mais voltou à minha aula. E ainda hoje fico me perguntando se segui por um caminho que "retirou" da aula de arte um adolescente ou se os que ficaram é que aprenderam algo sobre o que é viver nesse mundo "Demasiado Humano".

Ainda ronda sobre mim esta sombra que aflige muitos docentes. Eu poderia ter utilizado metodologias mil para trabalhar o filme, talvez devesse ter preparado mais os/as fruidores/espectadores para aquela aula, mas isso eu acho que nunca saberei. O que sei é que este acontecimento está sempre em minha mente quando estou preparando um módulo de aulas, uma aula específica e buscando imagens e filmes para compor um repertório. Mas, como busquei trabalhar pela filosofia da diferença utilizo um quase-mantra: faça rizoma, não enraíze, nem plante (DELEUZE e GATTARI, 1995). Isso me faz pensar que existe uma complexidade na relação que se estabelece entre o/a fruidor/espectador de uma obra e a obra em si, essa complexidade ativa forças criativas, subjetivas que podem revelar pulsões, metáforas, abstrações e poéticas das mais variadas formas, oportunizando transformação em todos os envolvidos no processo (ROSSI, 2003). Ou poderíamos ainda nos refugiar em Heródoto para lembrar que nunca mais seremos os mesmos após nos banharmos no rio e nem o rio será o mesmo.

Busco refletir este acontecimento pela vertente de partilha do sensível proposto por Jaques Rancière (2009) onde o político atua nas subjetividades, onde somente se participa da sociedade, da cultura, da arte, da política pelo engajamento, do ruído e do silêncio como forma de experiência. Então, quando aquele aluno xingou, não era a mim que ele queria atingir, mas atingiu, porque não passamos por esse tipo de situação ilesos. Seus gritos representavam silenciamentos sucessivos de como deveria se comportar, do que era esperado dele enquanto menino hétero. Aquela reação representou sua experiência de estar no mundo e ser pressionado por anos a fio a fazer o que se esperava dele: Uma reação violenta ao que é diferente do que lhe fora ensinado em casa. Cabe à sociedade como um todo assumir a responsabilidade da fratura e da desconstrução a essas expectativas tanto para o que é "masculino" quanto para o que é "feminino", para a sexualidade CIS ou não.

Como a arte, através das imagens que disponibiliza, pode ser agente de ação nas frestas? A resposta, suponho, está na própria pergunta. Nas frestas! Nos entre lugares, na partilha de subjetividades outras, que não estão dispostas nas prateleiras dos conhecimentos enlatados a 
que muitos professores se acostumaram, seja através dos livros didáticos, dos artistas consagrados neoclássicos _e até modernos, ou nos filmes cheios de clichês que muitas vezes são exibidos em sala para passar o tempo.

Diz-nos Rancière (2009) que, as "práticas estéticas" se vinculam às praticas artísticas que intervém nas maneiras de distribuição, nos fazeres, nas suas relações com maneiras de ser e formas de visibilidade, ou seja, a arte possibilita outras intervenções, fazeres, maneiras de ser e também contribui para uma elaboração e novos repertórios de visibilidade. Em resumo: Compõe-se política com imagens, pois elas revelam/escondem/ampliam/esvaziam as possibilidades de estar no mundo. Essa partilha da sensibilidade é corroborada por Judith Butler não nos termos que Rancière nos apresenta, mas pelo seu caráter político, a saber: " $O$ poder que a princípio parece externo, pressionado sobre o sujeito, pressionando o sujeito à subordinação, assume uma forma psíquica que constitui a identidade do sujeito" (BUTLER, 2011, p. 13 - tradução nossa). Dentro dos mecanismos que constituem as subjetividades do sujeito e sua identidade, estão as imagens com as quais este sujeito se relaciona cotidianamente e que lhe conferem também subjetividades e identidades. Com suas voltas especulares sobre si mesmas, as imagens podem promover as fratura de nossas certezas ontológicas.

Quiçá isto tenha acontecido no percurso desta aula que relatei, pois espero que tanto para minha prática docente, quanto para os discentes que ali se encontravam e principalmente para aquele que interrompeu o processo de fruição do filme aos gritos e xingamentos, tenham todos passado pelo processo, pela experimentação, pela inquietação, pela dor de ser confrontado e de ter as certezas sacudidas.

\section{Referências}

BUTLER, Judith. Mecanismos Psíquicos del Poder: Teorías sobre la sujeción. 3. ed. Barcelona - ES: Ediciones Cátedra, 2011. Trad. Jacqueline Cruz.

DELEUZE, Gilles; GUATTARI, Felix. Mil Platôs: capitalismo e esquizofrenia. v. 1. Rio de Janeiro: Editora 34, 1995. Trad. Aurélio Guerra Neto.

RANCIÈRE, Jacques. A Partilha do Sensível: estética e política. 2. ed. Rio de Janeiro: Editora 34, 2009. Trad. Mônica costa Netto.

ROSSI, Maria H. Wagner. Imagens que Falam: Leitura da arte na escola. 2. ed. Porto Alegre: Editora Mediação, 2003.

TADEU, Tomaz. A Filosofia de Deleuze e o Currículo. Goiânia: Faculdade de Artes Visuais, 2004. 74 p. (coleção Desenrêdos). 